\title{
Autochthonous Angiostrongylus cantonensis, Angiostrongylus vasorum and Aelurostrongylus abstrusus infections in native terrestrial gastropods from the Macaronesian Archipelago of Spain
}

\author{
Lisa Segeritz ${ }^{1}$ - Alejandro Cardona ${ }^{2} \cdot$ Anja Taubert $^{1} \cdot$ Carlos Hermosilla $^{1} \cdot$ Antonio Ruiz $^{2}$
}

Received: 14 January 2021 / Accepted: 30 May 2021 / Published online: 28 June 2021

(c) The Author(s) 2021

\begin{abstract}
The presence of zoonotic relevant Angiostrongylus cantonensis infections has recently been reported in rat final hosts and gastropod intermediate hosts in Tenerife, Spain. However, data on A. cantonensis, Angiostrongylus vasorum and Aelurostrongylus abstrusus prevalences in endemic gastropods for other islands of the Macaronesian Archipelago are still missing. In order to fill this gap, we conducted an epidemiological study on terrestrial native slug (Plutonia lamarckii) and snail (Cornu aspersum, Theba pisana, Rumina decollata) species in 27 selected locations of Tenerife, Gran Canaria, El Hierro, Lanzarote, La Palma and Fuerteventura. Overall, 131 terrestrial gastropods were collected in winter/spring season 2018/2019 and examined for the presence of metastrongyloid lungworm larvae via artificial digestion. The current data revealed a total prevalence of $4.6 \%$ for A. vasorum, 3.8\% for A. abstrusus and $0.8 \%$ for A. cantonensis. In Tenerife, three lungworm species were detected, thereby re-confirming A. cantonensis endemicity for this island. Prevalences of snails (C. aspersum) originating from El Hierro were 5\% for A. abstrusus and 15\% for A. vasorum, respectively, with larval burdens up to 290 larvae per specimen. This epidemiological study indicates the presence of human, canine and feline lungworm species in Macaronesia, Spain. The current data—particularly those on anthropozoonotic A. cantonensis—call for a regular large-scale monitoring on intermediate hosts, paratenic hosts and definitive hosts to prevent further spread of lungworm-related diseases in humans and animals.
\end{abstract}

Keywords Gastropod-borne disease $\cdot$ Lungworm infections · Angiostrongylus vasorum - Angiostrongylus cantonensis . Aelurostronglyus abstrusus $\cdot$ Metastrongyloid nematodes

\section{Introduction}

Angiostrongylus cantonensis, Angiostrongylus vasorum and Aelurostrongylus abstrusus represent lungworms of the family Metastrongyloidea, which can infect humans, domestic dogs and cats. Recent European surveys indicate that these parasites are spreading within Europe (Foronda et al. 2010;

Section Editor: Elizabeth Marie Warburton

Lisa Segeritz

Lisa.C.Segeritz@vetmed.uni-giessen.de

1 Institute of Parasitology, Biomedical Research Center Seltersberg (BFS), Justus Liebig University Giessen, 35392 Giessen, Germany

2 Parasitology Laboratory Unit, Faculty of Veterinary Medicine, University of Las Palmas de Gran Canaria, Arucas, Las Palmas, Spain
Jefferies et al. 2010a; Schnyder et al. 2017; Penagos-Tabares et al. 2020; Federspiel et al. 2020). The zoonotic parasite $A$. cantonensis is found in various rat final host species of Australia, China, India, Pakistan, vast areas of Southeast Asia, Pacific and Indian Ocean islands and South America. It is also endemic in Egypt, the Caribbean area and the southern tropical part of the USA. More recently, A. cantonensis has been reported from rats (Rattus rattus) (Foronda et al. 2010) and terrestrial gastropods (Martin-Alonso et al. 2011, 2015) of the island Tenerife, Macaronesian Archipelago, and additionally from two hedgehogs of the island Mallorca, Spain (Paredes-Esquivel et al. 2019), proving its geographic expansion into the previously non-endemic European regions (Federspiel et al. 2020). Neurotropic third-stage larvae (L3) of A. cantonensis are the etiological agent of human angiostrongyliasis, which is characterized by severe eosinophilic meningoencephalitis/encephalitis with sometime lethal outcome (Martin-Alonso et al. 2015; Federspiel et al. 2020). 
Humans become infected by oral ingestion of raw or undercooked terrestrial gastropods (i.e. slugs/snails) containing infective L3 or by consumption of undercooked paratenic hosts (i.e. amphibians, crabs, crayfishes). In rats, ingested L3 rapidly migrate through intestinal walls, spread haematogenously, reach cerebrum and cerebellum within 4-6 days post infectionem (p. i.), and moult into fourth-stage larvae (L4) which invade the subarachnoid space and migrate via blood circulation to the pulmonary artery and right heart. Conversely, in A. cantonensis-infected humans, neurotropic L4 can reach 1-2 mm in size and are often enclosed by granulomas in parenchyma of cerebrum, cerebellum or in the subarachnoid space, thereby causing severe tissue inflammation (Graeff-Teixeira et al. 2009; Wang et al. 2012; Barratt et al. 2016).

In contrast to A. cantonensis, the closely related parasite A. vasorum is the causative agent of cardiopulmonary disorders of domestic and wild canid species (Taubert et al. 2009; Traversa et al. 2010; Schnyder et al. 2017; Gillis-Germitsch et al. 2017b; Penagos-Tabares et al. 2018a, b; Lange et al. 2018a). As such, adult A. vasorum nematodes parasitize the right heart and pulmonary artery system of dogs (Schnyder et al. 2017; Penagos-Tabares et al. 2018a), wolves (Eleni et al. 2014; Hermosilla et al. 2017), coyotes (Bourque et al. 2005), jackals (Takács et al. 2014) and several fox species (Lima et al. 1994; Duarte et al. 2007; Morgan et al. 2008; Schug et al. 2018). Additionally, mustelids (e.g. ferrets, racoon dogs) and other carnivorous species may act as definitive hosts (Lemming et al. 2020). Canine angiostrongylosis might vary from subclinical cases to ophthalmic, nervous and severe cardiopulmonary disorders including life-threatening systemic coagulopathies (Taubert et al. 2009; Di Cesare and Traversa 2014; Schnyder et al. 2017).

Aelurostrongylus abstrusus is a relevant lungworm of domestic and wild felids with a worldwide distribution (Scott 1973; Traversa et al. 2008; Taubert et al. 2009; Jefferies et al. 2010b; Elsheikha et al. 2019). Clinical manifestations of feline aelurostrongylosis include typical signs of respiratory diseases, such as dyspnoea, mucopurulent nasal discharge, open-mouthed abdominal breathing, sneezing, coughing and wheezing (Traversa et al. 2008). Aelurostrongylus abstrusus was reported in various European (Traversa et al. 2008; Taubert et al. 2009; Jefferies et al. 2010b; Knaus et al. 2011) and South American (Penagos-Tabares et al. 2018a) countries and is infecting, besides domestic cats, also several felid wildlife species (West et al. 1977; Noronha et al. 2002; González et al. 2007; Penagos-Tabares et al. 2018a).

The lungworms A. cantonensis, A. vasorum and A. abstrusus have been considered neglected and underestimated in Europe (Foronda et al. 2010; Martin-Alonso et al. 2011, 2015; Lange et al. 2018a) and other geographic regions (Traversa et al. 2010; Penagos-Tabares et al. 2018a, 2019; Federspiel et al. 2020). Nowadays, due to an increased research focus on lungworms, occurrences of these nematodes are reported from several geographical areas of Europe (Morgan and Shaw 2010; Taylor et al. 2015; Barutzki et al. 2017; Maksimov et al. 2017). Since metastrongyloid lungworms require terrestrial gastropods as obligate intermediate hosts to complete their life cycles, knowledge on seasonal infections in gastropods seems crucial for a better understanding of the epidemiology of these parasitoses. Whilst a vast amount of data exists on lungworm infections in definitive hosts (Taubert et al. 2009; Wang et al. 2012; Barutzki and Schaper 2013; Di Cesare et al. 2015; Barratt et al. 2016; Gillis-Germitsch et al. 2017a; Schnyder et al. 2017), little has been reported on natural gastropod infections (Ferdushy et al. 2009; Majoros et al. 2010; Patel et al. 2014; Lange et al. 2018a, b; Penagos-Tabares et al. 2019, 2020; Dimzas et al. 2020). To our best knowledge, there is only one report on A. cantonensis-infected slugs/snails in Tenerife (MartinAlonso et al. 2015).

Therefore, the aim of this study was firstly to evaluate lungworm larval infections in native terrestrial gastropod populations, and secondly, to address a potential geographic expansion of these parasites into other islands of the Macaronesian Archipelago in Spain.

\section{Materials and methods}

\section{Study area and slug/snail collection}

As also true for the Spanish mainland, a temperate Mediterranean climate predominates in the Archipelago of Macaronesia (see Fig. 1). Rainfall can be scarce in distinct islands (i.e. Lanzarote and Fuerteventura), where prolonged dry seasons and hot summers are typical. Each island has an individual microclimate, based on a distinct geography and ecoepidemiology, including endemic vegetation and vertebrate/ invertebrate species diversity. The current terrestrial mollusc collection sites were diverse but semi-arid climate conditions were predominant (see Table 1). Thus, collection sites were mainly composed of xerophyts (e.g. cactus and euphorbia), grassland, shrubs, and also sub-tropical pine and laurel forests (in Tenerife, El Hierro and La Palma) with evergreen endemic trees, such as Pinus canariensis and broadleaf Lauraceae (e.g. Laurus novocanariensis and Persea indica).

Study areas included locations, where straying dogs, feral cats, black rats (Rattus rattus) and brown rats (Rattus norvegicus) were frequently present, since these mammals can potentially act as definitive hosts for human and canine angiostrongylosis as well as feline aelurostrongylosis/ troglostrongylosis.

Different native terrestrial gastropods, such as slugs, snails (Theba pisana, Cornu aspersum, Rumina decollata) 


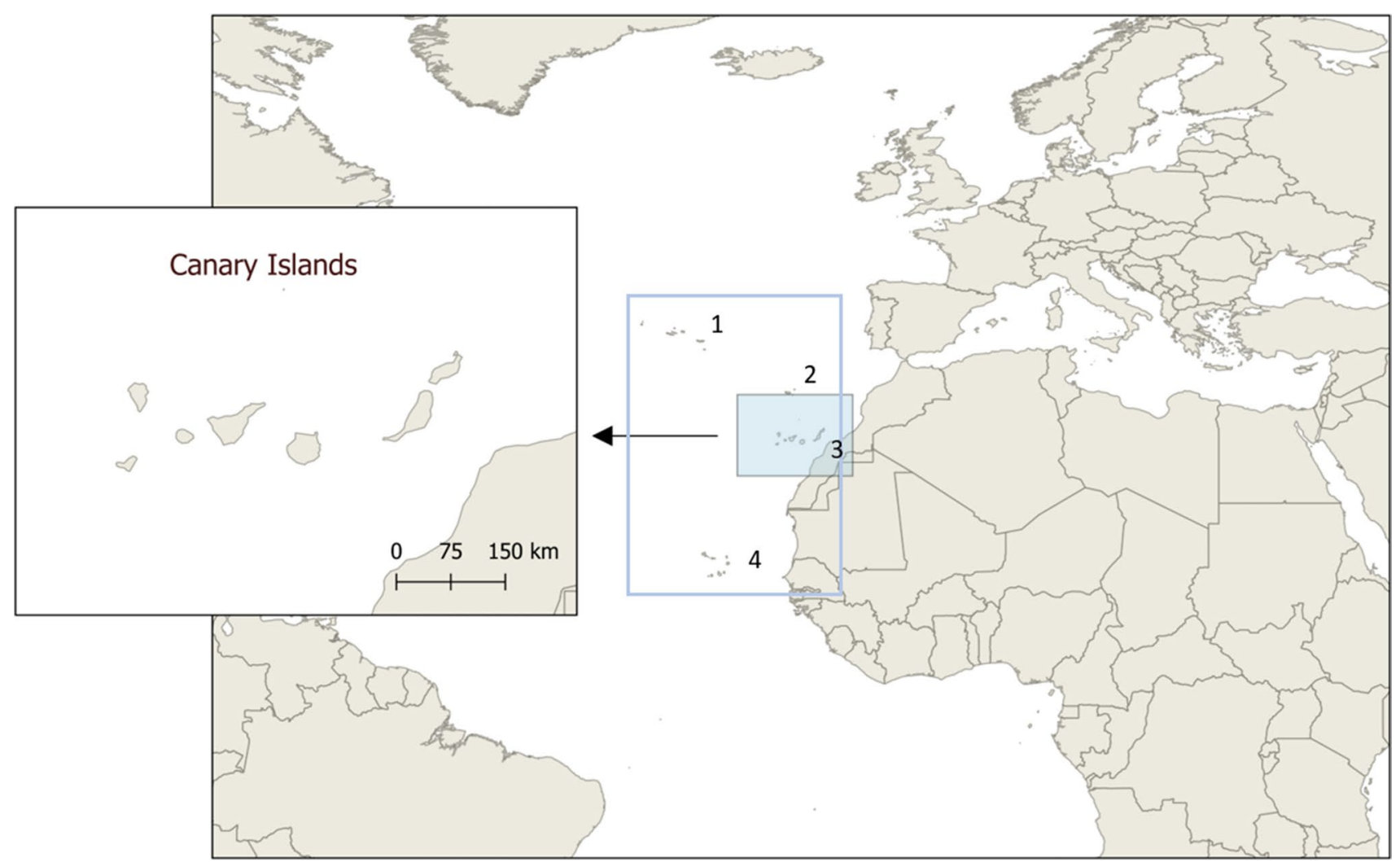

Fig. 1 The Macaronesian region: (1) Azores; (2) Madeira; (3) Canary Islands; (4) Cape Verde

and the so-called semi-slugs (Plutonia lamarckii), which are characterized by the appearance of slugs but are equipped with a small rudimental shell, were collected. Gastropod collection occurred mainly by hand at dawn or break of dawn. In total, 131 specimens were collected during December 2018 to April 2019 from Tenerife $(n=28)$, Gran Canaria $(n=23)$, Lanzarote $(n=20)$, El Hierro $(n=20)$ and Fuerteventura $(n=20)$, Archipelago of Macaronesia, Spain (24 $15^{\prime} 24^{\prime \prime} \mathrm{N}, 22^{\circ} 28^{\prime} 16^{\prime \prime} \mathrm{W}$; see Fig. 1 and Fig. 2). Furthermore, we also intensively searched on La Gomera, but failed to find gastropods.

Molluscs were weighted, individually stored in plastics bags, cryo-euthanized according to Lange et al. (2017) and stored frozen at $-20{ }^{\circ} \mathrm{C}$ at the Faculty of Veterinary Medicine, University of Las Palmas de Gran Canaria, Spain, until further investigations.

Before artificial digestion, gastropod species were identified based on their morphological characteristics according to literature (Nordsieck 2000; Martin-Alonso et al. 2015). Frozen gastropods were transferred to the Institute of Parasitology at Justus Liebig University Giessen (JLU), Giessen, Germany. According to current national animal protection laws of Spain, a permission for gastropod collection or their use for basic research purposes is not required.

\section{Gastropod digestion}

Frozen gastropods (P. lamarckii, C. aspersum, T. pisana, $R$. decollata) were cut into small pieces and immersed in digestion solution [10 g pepsin powder 2000 FIP-U/g (Robert Kind), $8.5 \mathrm{~g} \mathrm{NaCl}$ (Carl Roth), $30 \mathrm{~mL} \mathrm{HCl} \mathrm{37 \%} \mathrm{(Carl}$ Roth), adjusted with distilled water to $1 \mathrm{~L}$ ] according to Lange et al. (2018a, b) and Penagos-Tabares et al. (2020). Briefly, single gastropods were digested for $3 \mathrm{~h}$ at $37^{\circ} \mathrm{C}$ in sterile 50-mL plastic tubes (Greiner) under constant shaking conditions. Digested gastropod samples were sieved according to Lange et al. (2018a, b) through a 300- $\mu$ m metal sieve (Retsch, Haan, Germany) in order to remove any un-digested material, and afterwards passed through a $25-\mu \mathrm{m}$ metal sieve (Retsch, Haan, Germany).

\section{Morphological and morphometric identification of metastrongyloid larvae}

Remnants of the last sieving process were transferred into sterile $15-\mathrm{mL}$ Falcon tubes and pelleted at $40 \times g$ for $10 \mathrm{~min}$ at room temperature (RT). Pellets were resuspended and examined via an Olympus BH-2® microscope equipped with a digital camera (SC30®, Olympus). Metastrongyloid species and stages were identified 
Table 1 Characteristics of sampling locations, with corresponding numbers of collected and lungworm-positive detected gastropods from Macaronesia, Spain

\begin{tabular}{|c|c|c|c|c|c|c|}
\hline Location & Municipality & Vegetation & Climate* & Zone & $\begin{array}{l}\text { Collected } \\
\text { gastropods }\end{array}$ & $\begin{array}{l}\text { Lungworm- } \\
\text { positive } \\
\text { gastropods }\end{array}$ \\
\hline \multicolumn{7}{|l|}{ Gran Canaria } \\
\hline Lomo Apolinario & Las Palmas de Gran Canaria & Sweet spurge shrubland & BWh & Urban & 13 & 0 \\
\hline Altos Guía & Santa María de Guía & Sweet spurge shrubland & $\mathrm{Csc}$ & Rural & 5 & 0 \\
\hline Maspalomas & San Bartolomé de Tirajana & Hyper-arid tamarisk thicket & BWh & Urban & 2 & 0 \\
\hline Firgas & Firgas & Laurisilva & BSk & Rural & 3 & 0 \\
\hline \multicolumn{7}{|l|}{ Tenerife } \\
\hline Santa Cruz de Tenerife & Santa Cruz de Tenerife & Cardon spurge shrubland & BSh & Urban & 5 & 0 \\
\hline Tegueste & Tegueste & Laurisilva & $\mathrm{Cs}$ & Rural & 5 & 0 \\
\hline La Esperanza & El Rosario & Laurisilva & Cs & Rural & 5 & 4 \\
\hline Guía de Isora & Guía de Isora & Pine forest & Csb & Rural & 2 & 1 \\
\hline La Orotava & La Orotava & Laurisilva & $\mathrm{Csb}$ & Suburban & 4 & 1 \\
\hline Icod de los Vinos & Icod de los Vinos & Pine forest & $\mathrm{BSh}$ & Rural & 4 & 0 \\
\hline San Cristóbal de la Laguna & San Cristóbal de la Laguna & Laurisilva & $\mathrm{Csb}$ & Urban & 3 & 0 \\
\hline \multicolumn{7}{|l|}{ Lanzarote } \\
\hline Puerto del Carmen & Tías & Sweet spurge shrubland & BWh & Urban & 10 & 0 \\
\hline Arrieta & Haría & Sweet spurge shrubland & BWh & Suburban & 10 & 0 \\
\hline \multicolumn{7}{|l|}{ Fuerteventura } \\
\hline La Oliva & La Oliva & Cardon spurge shrubland & BWh & Rural & 10 & 0 \\
\hline Corralejo & La Oliva & Psammophilous communities & BWh & Rural & 10 & 0 \\
\hline \multicolumn{7}{|l|}{ La Palma } \\
\hline Fuencaliente & Fuencaliente & Pine forest & Csb & Rural & 2 & 0 \\
\hline Tijarafe & Tijarafe & Pine forest & $\mathrm{Csb}$ & Rural & 2 & 0 \\
\hline Los Llanos de Aridane & Los Llanos de Aridane & White broom shrubland & Csa & Urban & 2 & 0 \\
\hline Puntagorda & Puntagorda & Pine forest & $\mathrm{Csb}$ & Rural & 2 & 0 \\
\hline Santa Cruz de la Palma & Santa Cruz de la Palma & Cardon spurge shrubland & BSh & Urban & 6 & 0 \\
\hline Barlovento & Barlovento & Laurisilva & Csa & Rural & 6 & 0 \\
\hline \multicolumn{7}{|l|}{ El Hierro } \\
\hline La Frontera & La Frontera & Juniper woodland & BSh & Rural & 1 & 0 \\
\hline Isora & Valverde & Pine forest & $\mathrm{BSk}$ & Rural & 2 & 0 \\
\hline Moncanal & Valverde & Laurisilva & BSk & Rural & 3 & 0 \\
\hline San Andres & Valverde & Laurisilva & BSk & Rural & 5 & 0 \\
\hline Sabinosa & La Frontera & Juniper woodland & BSk & Rural & 3 & 0 \\
\hline Valverde & Valverde & Laurisilva & $\mathrm{BSk}$ & Rural & 3 & 3 \\
\hline Ruta del Garoé & Valverde & Laurisilva & BSk & Rural & 3 & 0 \\
\hline
\end{tabular}

*Köppen-Geiger climate classification:

$B S k$, cold semi-arid climate; $B S h$, hot semi-arid climate; $B W h$, hot desert climate; $C s$, Mediterranean climate; $C s a$, hot-summer Mediterranean climate; $C s b$, warm-summer Mediterranean climate; $C s c$, cold-summer Mediterranean climate

All climate data according to www.climate-data.org

All data about vegetation according to the book of Marcelino J. del Arco Aguilar and Octavio Rodríguez Delgado (2018) Vegetation of the Canary Islands

morphologically, documented individually by digital photography. Larvae were counted, carefully collected by pipetting under microscopic control and stored at $4{ }^{\circ} \mathrm{C}$ for further examinations. The body length and width, the oesophagus form (non-rhabditiform), the ratio of oesophagus to body lengths $(1: 3-1: 2)$ and the typical larval tail morphology were analysed as reported elsewhere (Lange et al. 2018a; Guilhon and Cens 1973; Giannelli et al. 2014; Martin-Alonso et al. 2015; Penagos-Tabares et al. 2018a) (see Fig. 3). 

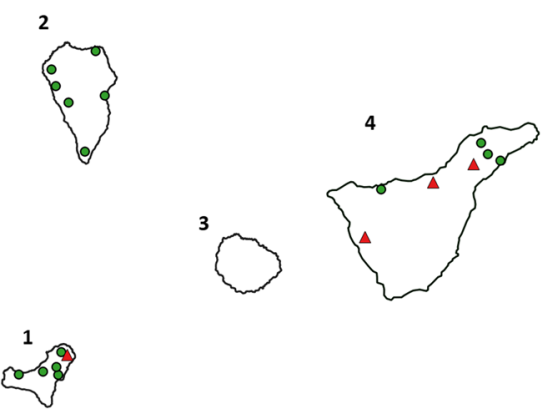

Fig. 2 Sampling locations. Green circle means locations with lungworm negative gastropod samples. Red triangle means locations with lungworm-positive gastropod samples. (1) El Hierro: La Frontera; Isora; Mocanal; San Andrés; Sabinosa; Valverde; Ruta del Goroé. (2) La Palma: Fuencaliente; Tijarafe; Los Llanos de Aridane; Puntagorda; Santa Cruz de la Palma; Barlovento (3) La Gomera (4) Ten-

\section{Molecular identification}

To confirm morphological findings, DNA from pooled metastrongyloid larvae of single gastropods was isolated using a commercial kit (Quiagen DNeasy Blood and Tissue $\left.\mathrm{Kit}{ }^{\circledR}\right)$ and analysed as described previously (Lange et al.
5

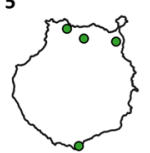

7

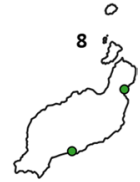

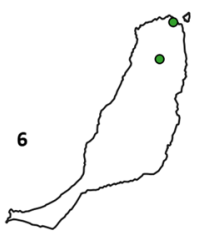

erife: Santa Cruz de Tenerife; Tegueste; La Esperanza; Guía de Isora; La Orotava; Icod de los Vinos; La Laguna (5) Gran Canaria: Las Palmas de Gran Canaria; Santa María de Guía; Maspalomas; Firgas (6) Fuerteventura: La Oliva; Corralejo (7) Lanzarote: Puerto del Carmen; Arrieta (8) La Graciosa

2018a, b; Penagos-Tabares et al. 2019, 2020). Molecular species confirmation was performed by running conventional PCRs with the universal nematode primers $\mathrm{NC1} /$ NC2 (Gasser et al. 1993) followed by species-specific realtime PCRs. A duplex real-time PCR for A. abstrusus and $T$. brevior was carried out, amplifying the internal transcribed
Fig. 3 Morphological characteristics of metastrongyloid larvae, found in gastropods from Macaronesia, Spain. Thirdstage larvae of Angiostrongylus cantonensis (A), Aelurostrongylus abstrusus (B) and Angiostrongylus vasorum $(\mathrm{C})$; panel D shows an A. vasorum secondstage larva, in the sheath of a first-stage larva; details of the posterior ends are shown in (a), (b), (c) and (d). The third-stage larva of A. cantonensis can be identified by its tail pointed tip (a), whereas the A. abstrusus L3 (b) has a terminal rounded knob and the A. vasorum L3 is characterized by a short digitiform posterior end (c). The tail of an A. vasorum $\mathrm{L} 1$ shows a dorsal spine (d). Scale bar (A, B, C, D) $40 \mu \mathrm{m}$; scale bar (a, b, c, d) $20 \mu \mathrm{m}$

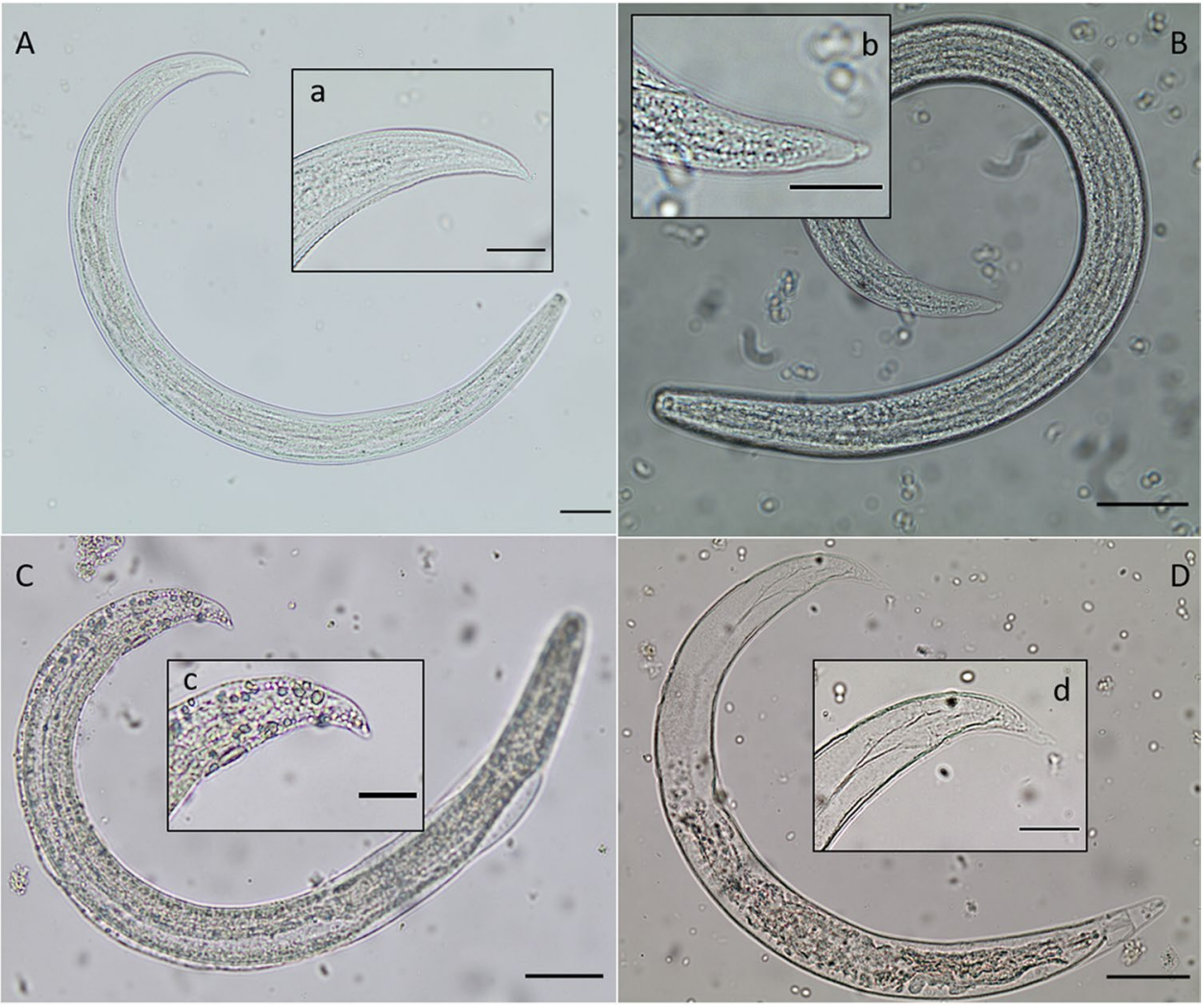


spacer 2 (ITS-2) region from the ribosomal DNA. This PCR was conducted, using the forward primers TrogloF and AeluroF and the single reverse primer MetR (Annoscia et al. 2014). The duplex real-time PCR for A. vasorum was performed, amplifying a partial ITS- 2 region as reported by Jefferies et al. (2009).

\section{Results}

\section{Prevalence of $A$. cantonensis, $A$. vasorum and $A$. aelurostrongylus in native gastropods}

Considering all samples from all regions, a total lungworm larvae prevalence of $6.9 \%(9 / 131)$ with a $95 \%$ confidence interval (CI) of 2.6-11.2 was calculated, based on microscopic identification. Lungworm larvae were present in gastropods from two out of six investigated islands (see Fig. 2 and Table 2), giving a total prevalence of $21.4 \%(6 / 28)$ (6.2-36.6 CI 95\%) in Tenerife and of 15\% (3/20) (0-30.6 CI 95\%) in El Hierro. In Tenerife, three lungworm-positive gastropod locations were identified, whereas in El Hierro only one collection site proved positive for lungworm larvae in gastropods, namely the municipality of Valverde.

The most common parasite was $A$. vasorum with a prevalence of $4.6 \%(6 / 131 ; 1-8.2$ CI 95\%) and A. abstrusus with a prevalence of $3.8 \%(5 / 131 ; 0.5-7.1$ CI $95 \%)$, followed by A. cantonensis $(0.8 \% ; 1 / 131 ; 0-2.3$ CI 95\%) (see Table 2$)$.

Unfortunately, the samples did not contain sufficient amplifiable DNA for molecular analyses. Therefore, for prevalence calculation, only microscopic-based data was used.

\section{Larval stages and burden in gastropods}

A high proportion of lungworm larvae in gastropod samples revealed as second-stage (L2, 50.3\%) or third-stage (L3, 46.2\%) larvae, whilst only $3.5 \%$ of the larvae were L1 (see Table 3). Of note, all white garden snails (T. pisana; $n=51$ ) proved negative for lungworm larvae. Thus, lungworm larvae were exclusively found in native semi-slugs [P. lamarckii (2/5)], common garden snails [C. aspersum
(5/63)], decollate snails [R. decollata (1/5)] and one unidentified slug species (1/7).

Larval burden per specimen varied considerably from one to 290 larvae for individual gastropods. Overall, 55.6\% (5/9) of metastrongyloid-positive gastropods contained less than 10 larvae. Interestingly, the two molluscs ( $P$. lamarckii and C. aspersum) with the highest larval burden (138 and 290 larvae, respectively) both showed a double infection with A. vasorum and A. abstrusus. Coinfections were observed in three gastropods. One gastropod (C. aspersum) contained larvae, which could not be identified due to their destroyed cuticles, oesophagus or tails. Besides lungworm larvae, some typical gastropod-specific parasitic nematodes of the genus Phasmarhabditis were detected, but not further considered in this study.

\section{Discussion and conclusion}

The present epidemiological study offers conclusive evidence that native gastropod species in Macaronesia may act as suitable intermediate hosts for human and canine angiostrongylosis and feline aelurostrongylosis, under natural habitat conditions. It further represents the first report in Spain on A. vasorum and A. abstrusus infections, occurring in terrestrial intermediate hosts, thereby underlining their role in the epidemiology of these neglected parasitoses. It also confirms recent reports on the occurrence of anthropozoonotic-relevant $A$. cantonensis in Tenerife. The biodiversity of terrestrial gastropod species in this particular region of Spain gives evidence that native molluscs will most probably contribute to expansion of zoonotic- and veterinaryrelevant lungworms into other islands where infections of humans, dogs and cats with these lungworms have not yet been reported.

The distribution pattern of metastrongyloid-positive gastropods in Tenerife indicated a widespread geographical extension of these parasites on this island. Whilst other related studies described an occurrence of A. cantonensis in the northeastern part of the island (Foronda et al. 2010; Martin-Alonso et al. 2011, 2015), here we detected A. cantonensis infections in the municipality Guia de Isora, which is situated in the western part of Tenerife. A. cantonensis
Table 2 Prevalence of lungworm species in natural intermediate host populations in Macaronesia

\begin{tabular}{lccc}
\hline Lungworm species & \multicolumn{1}{l}{ Total } & \multicolumn{1}{l}{ Tenerife } & \multicolumn{1}{l}{ El Hierro } \\
& $\mathrm{P}(+/ \mathrm{n})[95 \% \mathrm{CI}]$ & $\mathrm{P}(+/ \mathrm{n})[95 \% \mathrm{CI}]$ & $\mathrm{P}(+/ \mathrm{n})[95 \% \mathrm{CI}]$ \\
\hline All lungworm species & $6.9(9 / 131)[2.6-11.2]$ & $21.4(6 / 28)[6.2-36.6]$ & $15(3 / 20)[0-30.6]$ \\
Angiostrongylus vasorum & $4.6(6 / 131)[1-8.2]$ & $10.7(3 / 28)[0-22.1]$ & $15(3 / 20)[0-30.6]$ \\
Aelurostongylus abstrusus & $3.8(5 / 131)[0.5-7.1]$ & $14.3(4 / 28)[1.3-27.3]$ & $5(1 / 20)[0-14.6]$ \\
$\begin{array}{l}\text { Angiostrongylus canton- } \\
\text { ensis }\end{array}$ & $0.8(1 / 131)[0-2.3]$ & $3.6(1 / 28)[0-10.5]$ & $0(0 / 20)[0]$ \\
\hline
\end{tabular}

$P$, prevalence in $\% ; n$, number of analysed gastropods; + , number of positive samples; $C I$, confidence interva 
Table 3 Metastrongyloid-positive samples with the identified lungworm species, the number of detected larval stages, the larval burden and information on the gastropod species and the location, vegetation and climate where the sample originates from

\begin{tabular}{|c|c|c|c|c|c|c|c|c|c|}
\hline \multirow[t]{2}{*}{ Location } & \multirow[t]{2}{*}{ Vegetation } & \multirow[t]{2}{*}{ Climate* } & \multirow[t]{2}{*}{ Gastropod species } & \multirow[t]{2}{*}{ Detected lungworm species } & \multicolumn{4}{|c|}{ Detected larval stages } & \multirow[t]{2}{*}{ Larval burden } \\
\hline & & & & & L1 & $\mathrm{L} 2$ & L3 & Unknown & \\
\hline \multicolumn{10}{|l|}{ Tenerife } \\
\hline La Esperanza & Laurisilva & Csb & R. decollata & A. abstrusus & 2 & 6 & 1 & & 9 \\
\hline La Esperanza & Laurisilva & $\mathrm{Csb}$ & C. aspersum & A. abstrusus & 0 & 1 & 0 & & 1 \\
\hline La Esperanza & Laurisilva & $\mathrm{Csb}$ & P. lamarckii & A. abstrusus & 0 & 1 & 32 & & 33 \\
\hline La Esperanza & Laurisilva & $\mathrm{Csb}$ & P. lamarckii & $\begin{array}{l}\text { A. abstrusus } \\
\text { A. vasorum }\end{array}$ & 0 & 41 & 97 & & 138 \\
\hline Guia de Isora & Pine forest & $\mathrm{Csb}$ & Slug** & A. vasorum & 0 & 4 & 1 & & 5 \\
\hline La Orotava & Laurisilva & Csb & C. aspersum & $\begin{array}{l}\text { A. cantonensis } \\
\text { A. vasorum }\end{array}$ & 3 & 12 & 23 & & 38 \\
\hline \multicolumn{10}{|l|}{ El Hierro } \\
\hline Valverde & Laurisilva & BSk & C. aspersum & $\begin{array}{l}\text { A. abstrusus } \\
\text { A. vasorum }\end{array}$ & 11 & 159 & 56 & 64 & 290 \\
\hline Valverde & Laurisilva & BSk & C. aspersum & A. vasorum & 0 & 2 & 0 & & 2 \\
\hline \multirow[t]{4}{*}{ Valverde } & Laurisilva & $\mathrm{BSk}$ & C. aspersum & A. vasorum & 0 & 3 & 0 & & 3 \\
\hline & & & & Total & 16 & 229 & 210 & 64 & 519 \\
\hline & & & & Mean & 5.3 & 25.4 & 35.0 & & 57.7 \\
\hline & & & & Distribution in $\%$ & 3.5 & 50.3 & 46.2 & & \\
\hline
\end{tabular}

*Köppen-Geiger climate classification:

$C s b$, warm-summer Mediterranean climate; BSk, cold semi-arid climate

All climate data according to www.climate-data.org

**Unidentified species.

infections remained restricted to this island, thereby confirming its geographic endemicity (Foronda et al. 2010; Martin-Alonso et al. 2011, 2015), but denying further expansion into other archipelago islands.

Since the Canary Archipelago has a good infrastructure and is popular for tourism, an oversea transportation system by ferries is operated between the islands; thereby, facilitating transmission of lungworm-infected definitive hosts is more likely. Accordingly, we expected to detect more lungworm-positive islands/locations. In Gran Canaria, the second most populated and a well-travelled island of the Canary Archipelago, aelurostrongylosis was diagnosed 2016 for the first time in feral cats (Rodriguez-Ponce et al. 2016). No A. abstrusus-infected gastropods were found in the current study on this island. One explanation for this result may be the limited number of analysed molluscs. The presence of gastropods and their parasite burden seems to be dependent on different climatic, ecological and environmental factors (Lv et al. 2006; Ferdushy et al. 2010; Giannelli et al. 2016). Furthermore, individual and species-specific coprophilic/ coprophagic behaviour in gastropods plays a role in the intermediate host capability to become infected by lungworm larvae. As gastropods are humidity dependent, finding them, in locations with vast semi-arid areas and valleys, as observed in Gran Canaria, is challenging. In the relatively humid island of the Canary Archipelago, La Gomera, which represents an apparently good habitat for gastropods, we expected to find a richer mollusc population. However, on this island, no gastropods were found despite two excursion efforts into different geographic locations.

The current data showed both lungworm coinfections and high parasitic burden in single Macaronesian gastropods. Thus, approximately half of the infected gastropods (5/9) comprised more than one lungworm species. Assuming that a longer exposure to faeces, covering metastrongyloid larvae leads to a higher probability for gastropods to become infected, we also expect that the occurrence of coinfections and the larval burden are dependent on this parameter. Besides age, also coprophagic preferences in oral uptake influence gastropod's exposure to infective L1. Therefore, factors affecting coprophagic behaviour in gastropods should be addressed in future studies. All here investigated metastrongyloid lungworms show a rather broad intermediate host spectrum, implicating that multiple intermediate hosts might exist at current sampling sites. Further studies on complex parasite-intermediate host interactions are currently planned to better understand gastropod-derived innate immune reactions against these larval stages. Consistently, it was recently demonstrated that gastropod-derived haemocytes seem capable to rapidly cast the so-called invertebrate extracellular 
phagocyte traps (InEPTs), mainly composed of extruded chromatin decorated with anti-microbial components, not only against motile larval stages of $A$. vasorum but also against A. abstrusus (Lange et al. 2017; Penagos-Tabares et al. 2018b), thereby demonstrating similarities to mammalian-derived neutrophil extracellular traps (NETs) against parasites (Silva et al. 2016; Villagra-Blanco et al. 2019). Since DNA isolation of a single larva is challenging and some detected larvae of the current study were in very poor conditions, DNA amplifying failed. Furthermore, this might be linked, besides to the DNA inhibitory effects deriving from snail tissue, to InEPTs-derived effector mechanisms including degranulation, reactive oxygen species (ROS) generation and encapsulation in vivo, resulting in partial or complete larval degradation (Penagos-Tabares et al. 2018b). Consequently, early host innate immunity and biodiversity of endemic intermediate gastropod hosts should be taken into account to better understand biology, distribution and expansion of human and canine/feline lungworms within the Macaronesian Archipelago and elsewhere. Considering the unique endemic vegetation and specific fauna as well as the local situation with high populations of feral dogs, cats and rats (Nogales et al. 2004; Medina and Nogales 2009; Martin-Alonso et al. 2011, 2015; Rodriguez-Ponce et al. 2016; Carretón et al. 2020), large-scale epidemiological surveys are needed, addressing definitive hosts (dogs, cats, rats) and gastropods as well as paratenic hosts (birds, reptiles, rodents) within this archipelago. Preventive education on this neglected parasitosis as well as food inspections is necessary, as snail consumption by humans is a common practice in Macaronesia. Thus, this work aims to raise awareness of veterinary surgeons, physicians and public health authorities not only in Macaronesia but also in other regions with similar climatic conditions.

Acknowledgements We are grateful to Christine Henrich, Juan Velez and Dr. Ivan Conejeros (Institute of Parasitology, Justus Liebig University Giessen, Germany) for their excellent help in processing gastropod samples, helping to perform molecular analyses and their precious advice.

Author contribution AR, AT and $\mathrm{CH}$ designed the survey. AR and AC collected the samples. LS and AC processed the slugs/snails and carried out microscopy analyses. LS performed the gastropod molecular analyses. LS, AR, AT and CH wrote the manuscript. AT, CH and AR revised the manuscript. All authors read and approved the final manuscript.

Funding Open Access funding enabled and organized by Projekt DEAL. This research was funded by the Institute of Parasitology, Justus Liebig University Giessen, Germany.

\section{Declarations}

Ethical statement Not applicable.
Conflict of interest The authors declare no competing interests. Animal welfare Not applicable

Open Access This article is licensed under a Creative Commons Attribution 4.0 International License, which permits use, sharing, adaptation, distribution and reproduction in any medium or format, as long as you give appropriate credit to the original author(s) and the source, provide a link to the Creative Commons licence, and indicate if changes were made. The images or other third party material in this article are included in the article's Creative Commons licence, unless indicated otherwise in a credit line to the material. If material is not included in the article's Creative Commons licence and your intended use is not permitted by statutory regulation or exceeds the permitted use, you will need to obtain permission directly from the copyright holder. To view a copy of this licence, visit http://creativecommons.org/licenses/by/4.0/.

\section{References}

Annoscia G, Latrofa MS, Campbell BE et al (2014) Simultaneous detection of the feline lungworms Troglostrongylus brevior and Aelurostrongylus abstrusus by a newly developed duplex-PCR. Vet Parasitol 199:172-178. https://doi.org/10.1016/j.vetpar.2013.10.015

Barratt J, Chan D, Sandaradura I, et al (2016) Angiostrongylus cantonensis: a review of its distribution, molecular biology and clinical significance as a human pathogen. Parasitology 143:1087-1118. https://doi.org/10.1017/S0031182016000652

Barutzki D, Schaper R (2013) Occurrence and regional distribution of Aelurostrongylus abstrusus in cats in Germany. Parasitol Res 112:855-861. https://doi.org/10.1007/s00436-012-3207-0

Barutzki D, Dyachenko V, Schaper R (2017) Lungworms in Germany 2002-2016: is there an increase in occurrence and geographical spread? Parasitol Res 116:11-30. https://doi.org/10.1007/ s00436-017-5488-9

Bourque A, Whitney H, Conboy G (2005) Angiostrongylus vasorum infection in a coyote (Canis latrans) from Newfoundland and Labrador, Canada. J Wildl Dis 41:816-819. https://doi.org/10.7589/ 0090-3558-41.4.816

Carretón E, Morchón R, Falcón-Cordón Y et al (2020) First epidemiological survey of Angiostrongylus vasorum in domestic dogs from Spain. Parasit Vectors 13:306. https://doi.org/10.1186/ s13071-020-04180-5

del Arco Aguilar MJ, Rodríguez Delgado O (2018) Vegetation of the Canary Islands. Springer International Publishing, Cham

Di Cesare A, Di Francesco G, Frangipane di Regalbono A, et al (2015) Retrospective study on the occurrence of the feline lungworms Aelurostrongylus abstrusus and Troglostrongylus spp. in endemic areas of Italy. Vet J Lond Engl 1997 203:233-238. https://doi.org/ 10.1016/j.tvj1.2014.12.010

Di Cesare A, Traversa D (2014) Canine angiostrongylosis: recent advances in diagnosis, prevention, and treatment. Vet Med Auckl NZ 5:181-192. https://doi.org/10.2147/VMRR.S53641

Dimzas D, Morelli S, Traversa D et al (2020) Intermediate gastropod hosts of major feline cardiopulmonary nematodes in an area of wildcat and domestic cat sympatry in Greece. Parasit Vectors 13:345. https://doi.org/10.1186/s13071-020-04213-z

Duarte FH, Vieira FM, Louzada GL et al (2007) Occurrence Angiostrongylus vasorum (Baillet, 1866) (Nematoda, Angiostrongylidae) in Cerdocyon thous Linnaeus, 1766 (Carnivora, Canidae) in Minas Gerais State Brazil. Arq Bras Med Veterinária E Zootec 59:10861088. https://doi.org/10.1590/S0102-09352007000400042

Eleni C, De Liberato C, Azam D et al (2014) Angiostrongylus vasorum in wolves in Italy. Int J Parasitol Parasites Wildl 3:12-14. https:// doi.org/10.1016/j.ijppaw.2013.10.003 
Elsheikha HM, Wright I, Wang B, Schaper R (2019) Prevalence of feline lungworm Aelurostrongylus abstrusus in England. Vet Parasitol Reg Stud Rep 16:100271. https://doi.org/10.1016/j.vprsr. 2019.100271

Federspiel F, Skovmand S, Skarphedinsson S (2020) Eosinophilic Meningitis due to Angiostrongylus cantonensis in Europe. Int $\mathrm{J}$ Infect Dis. https://doi.org/10.1016/j.ijid.2020.01.012

Ferdushy T, Kapel CMO, Webster P et al (2009) The occurrence of Angiostrongylus vasorum in terrestrial slugs from forests and parks in the Copenhagen area, Denmark. J Helminthol 83:379_ 383. https://doi.org/10.1017/S0022149X09377706

Ferdushy T, Kapel CMO, Webster P et al (2010) The effect of temperature and host age on the infectivity and development of Angiostrongylus vasorum in the slug Arion lusitanicus. Parasitol Res 107:147-151. https://doi.org/10.1007/s00436-010-1850-x

Foronda P, López-González M, Miquel J et al (2010) Finding of Parastrongylus cantonensis (Chen, 1935) in Rattus rattus in Tenerife, Canary Islands (Spain). Acta Trop 114:123-127. https://doi.org/ 10.1016/j.actatropica.2010.02.004

Gasser RB, Chilton NB, Hoste H, Beveridge I (1993) Rapid sequencing of rDNA from single worms and eggs of parasitic helminths. Nucleic Acids Res 21:2525-2526

Giannelli A, Ramos RAN, Annoscia G, Di Cesare A, Colella V, Brianti E, Dantas-Torres F, Mutafchiev Y, Otranto D (2014) Development of the feline lungworms and in snails. Parasitology 141(4):563-569

Giannelli A, Cantacessi C, Colella V et al (2016) Gastropod-borne helminths: a look at the snail-parasite interplay. Trends Parasitol 32:255-264. https://doi.org/10.1016/j.pt.2015.12.002

Gillis-Germitsch N, Kapel CMO, Thamsborg SM et al (2017a) Hostspecific serological response to Angiostrongylus vasorum infection in red foxes (Vulpes vulpes): implications for parasite epidemiology. Parasitology 144:1144-1153. https://doi.org/10.1017/ S0031182017000427

Gillis-Germitsch N, Manser MB, Hilbe M, Schnyder M (2017b) Meerkats (Suricata suricatta), a new definitive host of the canid nematode Angiostrongylus vasorum. Int J Parasitol Parasites Wildl 6:349-353. https://doi.org/10.1016/j.ijppaw.2017.10.002

González P, Carbonell E, Urios V, Rozhnov VV (2007) Coprology of Panthera tigris altaica and Felis bengalensis euptilurus from the Russian Far East. J Parasitol 93:948-950. https://doi.org/10. 1645/GE-3519RN.1

Graeff-Teixeira C, da Silva ACA, Yoshimura K (2009) Update on eosinophilic meningoencephalitis and its clinical relevance. Clin Microbiol Rev 22:322-348. https://doi.org/10.1128/CMR. 00044-08

Hermosilla C, Kleinertz S, Silva LMR et al (2017) Protozoan and helminth parasite fauna of free-living Croatian wild wolves (Canis lupus) analyzed by scat collection. Vet Parasitol 233:14-19. https://doi.org/10.1016/j.vetpar.2016.11.011

Jefferies R, Morgan ER, Shaw SE (2009) A SYBR green real-time PCR assay for the detection of the nematode Angiostrongylus vasorum in definitive and intermediate hosts. Vet Parasitol 166:112-118. https://doi.org/10.1016/j.vetpar.2009.07.042

Jefferies R, Shaw SE, Willesen J et al (2010a) Elucidating the spread of the emerging canid nematode Angiostrongylus vasorum between Palaearctic and Nearctic ecozones. Infect Genet Evol 10:561-568. https://doi.org/10.1016/j.meegid.2010.01.013

Jefferies R, Vrhovec MG, Wallner N, Catalan DR (2010b) Aelurostrongylus abstrusus and Troglostrongylus sp. (Nematoda: Metastrongyloidea) infections in cats inhabiting Ibiza. Spain Vet Parasitol 173:344-348. https://doi.org/10.1016/j.vetpar. 2010.06.032

Knaus M, Kusi I, Rapti D et al (2011) Endoparasites of cats from the Tirana area and the first report on Aelurostrongylus abstrusus
(Railliet, 1898) in Albania. Wien Klin Wochenschr 123(Suppl 1):31-35. https://doi.org/10.1007/s00508-011-1588-1

Lange MK, Penagos-Tabares F, Muñoz-Caro T et al (2017) Gastropod-derived haemocyte extracellular traps entrap metastrongyloid larval stages of Angiostrongylus vasorum, Aelurostrongylus abstrusus and Troglostrongylus brevior. Parasit Vectors 10:50. https://doi.org/10.1186/s13071-016-1961-z

Lange MK, Penagos-Tabares F, Hirzmann J et al (2018a) Prevalence of Angiostrongylus vasorum, Aelurostrongylus abstrusus and Crenosoma vulpis larvae in native slug populations in Germany. Vet Parasitol 254:120-130. https://doi.org/10.1016/j.vetpar. 2018.03.011

Lange MK, Penagos-Tabares F, Vélez J et al (2018b) Regional report on Angiostrongylus vasorum in Colombia: genetic similarity to European lineage. Vet Parasitol Reg Stud Rep 13:21-23. https:// doi.org/10.1016/j.vprsr.2018.03.004

Lemming L, Jørgensen AC, Nielsen LB et al (2020) Cardiopulmonary nematodes of wild carnivores from Denmark: do they serve as reservoir hosts for infections in domestic animals? Int J Parasitol Parasites Wildl 13:90-97. https://doi.org/10.1016/j. ijppaw.2020.08.001

Lima WS, Guimaraes MP, Lemos IS (1994) Occurrence of Angiostrongylus vasorum in the lungs of the Brazilian fox Dusicyon vetulus. J Helminthol 68:87. https://doi.org/10.1017/s0022149x00013547

Lv S, Zhou X-N, Zhang Y et al (2006) The effect of temperature on the development of Angiostrongylus cantonensis (Chen 1935) in Pomacea canaliculata (Lamarck 1822). Parasitol Res 99:583-587. https://doi.org/10.1007/s00436-006-0198-8

Majoros G, Fukár O, Farkas R (2010) Autochtonous infection of dogs and slugs with Angiostrongylus vasorum in Hungary. Vet Parasitol 174:351-354. https://doi.org/10.1016/j.vetpar.2010.09.012

Maksimov P, Hermosilla C, Taubert A et al (2017) GIS-supported epidemiological analysis on canine Angiostrongylus vasorum and Crenosoma vulpis infections in Germany. Parasit Vectors 10:108. https://doi.org/10.1186/s13071-017-2054-3

Martin-Alonso A, Foronda P, Quispe-Ricalde MA et al (2011) Seroprevalence of Angiostrongylus cantonensis in wild rodents from the Canary Islands. PLoS ONE 6:e27747. https://doi.org/10.1371/ journal.pone.0027747

Martin-Alonso A, Abreu-Yanes E, Feliu C et al (2015) Intermediate hosts of Angiostrongylus cantonensis in Tenerife. Spain PLOS ONE 10:e0120686. https://doi.org/10.1371/journal.pone.0120686

Medina F, Nogales M (2009) A review on the impacts of feral cats (Felis silvestris catus) in the Canary Islands: implications for the conservation of its endangered fauna. Biodivers Conserv 18:829 846. https://doi.org/10.1007/s10531-008-9503-4

Morgan E, Shaw S (2010) Angiostrongylus vasorum infection in dogs: continuing spread and developments in diagnosis and treatment. J Small Anim Pract 51:616-621. https://doi.org/10.1111/j.17485827.2010.01000.x

Morgan ER, Tomlinson A, Hunter S et al (2008) Angiostrongylus vasorum and Eucoleus aerophilus in foxes (Vulpes vulpes) in Great Britain. Vet Parasitol 154:48-57. https://doi.org/10.1016/j.vetpar. 2008.02.030

Nogales M, Martín A, Tershy BR et al (2004) A review of feral cat eradication on islands. Conserv Biol 18:310-319

Nordsieck R (2000) Die lebende Welt der Weichtiere. http://www. weichtiere.at/index.html. Accessed 27 Apr 2020

Noronha D, Vicente JJ, Pinto RM (2002) A survey of new host records for nematodes from mammals deposited in the Helminthological Collection of the Oswaldo Cruz Institute (CHIOC). Rev Bras Zool 19:945-949. https://doi.org/10.1590/S0101-81752002000300032

Penagos-Tabares F, Lange MK, Chaparro-Gutiérrez JJ et al (2018a) Angiostrongylus vasorum and Aelurostrongylus abstrusus: neglected and underestimated parasites in South America. Parasit Vectors 11:208. https://doi.org/10.1186/s13071-018-2765-0 
Penagos-Tabares F, Lange MK, Seipp A et al (2018b) Novel approach to study gastropod-mediated innate immune reactions against metastrongyloid parasites. Parasitol Res 117:1211-1224. https:// doi.org/10.1007/s00436-018-5803-0

Penagos-Tabares F, Lange MK, Vélez J et al (2019) The invasive giant African snail Lissachatina fulica as natural intermediate host of Aelurostrongylus abstrusus, Angiostrongylus vasorum, Troglostrongylus brevior, and Crenosoma vulpis in Colombia. PLoS Negl Trop Dis 13:e0007277. https://doi.org/10.1371/journal. pntd.0007277

Penagos-Tabares F, Groß KM, Hirzmann J et al (2020) Occurrence of canine and feline lungworms in Arion vulgaris in a park of Vienna: first report of autochthonous Angiostrongylus vasorum, Aelurostrongylus abstrusus and Troglostrongylus brevior in Austria. Parasitol Res 119:327-331. https://doi.org/10.1007/ s00436-019-06527-z

Paredes-Esquivel C, Sola J, Delgado-Serra S, et al (2019) Angiostrongylus cantonensis in North African hedgehogs as vertebrate hosts, Mallorca, Spain, October 2018. Eurosurveillance 24. https://doi. org/10.2807/1560-7917.ES.2019.24.33.1900489

Patel Z, Gill AC, Fox MT et al (2014) Molecular identification of novel intermediate host species of Angiostrongylus vasorum in Greater London. Parasitol Res 113:4363-4369. https://doi.org/10.1007/ s00436-014-4111-6

Rodriguez-Ponce E, Gonzalez J, Felipe M, et al (2016) Epidemiological survey of zoonotic helminths in feral cats in Gran Canaria island (Macaronesian archipelago-Spain). Acta Parasitol 61. https://doi.org/10.1515/ap-2016-0059

Schnyder M, Bilbrough G, Hafner C, Schaper R (2017) Angiostrongylus vasorum, "The French Heartworm": a serological survey in dogs from France introduced by a brief historical review. Parasitol Res 116:31-40. https://doi.org/10.1007/s00436-017-5489-8

Schug K, Krämer F, Schaper R et al (2018) Prevalence survey on lungworm (Angiostrongylus vasorum, Crenosoma vulpis, Eucoleus aerophilus) infections of wild red foxes (Vulpes vulpes) in central Germany. Parasit Vectors 11:85. https://doi.org/10.1186/ s13071-018-2672-4

Scott DW (1973) Current knowledge of aelurostrongylosis in the cat. Literature review and case reports. Cornell Vet 63:483-500
Silva LMR, Muñoz-Caro T, Burgos RA et al (2016) Far beyond phagocytosis: phagocyte-derived extracellular traps act efficiently against protozoan parasites in vitro and in vivo. Mediators Inflamm 2016:e5898074. https://doi.org/10.1155/2016/5898074

Takács A, Szabó L, Juhász L et al (2014) Data on the parasitological status of golden jackal (Canis aureus L., 1758) in Hungary. Acta Vet Hung 62:33-41. https://doi.org/10.1556/AVet.2013.058

Taubert A, Pantchev N, Vrhovec MG et al (2009) Lungworm infections (Angiostrongylus vasorum, Crenosoma vulpis, Aelurostrongylus abstrusus) in dogs and cats in Germany and Denmark in 2003-2007. Vet Parasitol 159:175-180. https://doi.org/10.1016/j. vetpar.2008.10.005

Taylor CS, Gato RG, Learmount J et al (2015) Increased prevalence and geographic spread of the cardiopulmonary nematode Angiostrongylus vasorum in fox populations in Great Britain. Parasitology 142:1190-1195. https://doi.org/10.1017/S0031182015000463

Traversa D, Lia RP, Iorio R et al (2008) Diagnosis and risk factors of Aelurostrongylus abstrusus (Nematoda, Strongylida) infection in cats from Italy. Vet Parasitol 153:182-186. https://doi.org/10. 1016/j.vetpar.2008.01.024

Traversa D, Di Cesare A, Conboy G (2010) Canine and feline cardiopulmonary parasitic nematodes in Europe: emerging and underestimated. Parasit Vectors 3:62. https://doi.org/10.1186/ 1756-3305-3-62

Villagra-Blanco R, Silva L, Conejeros I, et al (2019) Pinniped-and cetacean-derived ETosis contributes to combating emerging apicomplexan parasites (Toxoplasma gondii, Neospora caninum) circulating in marine environments. Biology 8. https://doi.org/ 10.3390/biology8010012

Wang Q-P, Wu Z-D, Wei J et al (2012) Human Angiostrongylus cantonensis: an update. Eur J Clin Microbiol Infect Dis 31:389-395. https://doi.org/10.1007/s10096-011-1328-5

West B, Wilson P, Hatch C (1977) Aelurostrongylus abstrusus infection in the Cheetah. J Helminthol 51:210-211. https://doi.org/10.1017/ s0022149x00007525

Publisher's note Springer Nature remains neutral with regard to jurisdictional claims in published maps and institutional affiliations. 